\title{
Automatic power factor and speed control of three phase induction motor using programmable logic control
}

\author{
C. B. Venkatramanan ${ }^{1 *}$, S. Padma² \\ ${ }^{1}$ Assistant Professor, ${ }^{l}$ EEE Dept, ${ }^{2}$ Professor, ${ }^{2}$ Head of EEE Dept. \\ ${ }^{1,2}$ Sona College of Technology, Salem, India \\ *Corresponding Author E-mail:venkataraman@sonatech.ac.in
}

\begin{abstract}
This paper proposes an efficient speed control and power factor improvement of three phase induction motor using PLC. Hardware and software are implemented in this work. The hardware consists of power-circuit and control-circuit of the working system and software PLC programs were developed. Power factor correction is applied to enhance the efficiency of transmission network. Three phase induction motor is used which acts as inductive load which produce variation in power factor. The power factor of the supply line is directly monitored by the Multi-Function Meter which is connected in parallel to the supply line. The value of the capacitance (capacitor bank) for correcting the power factor variation due to induction motor is found out separately. Capacitor bank for the respective load is triggered by using PLC, which connects the capacitor bank parallel to the load and thereby bringing the power factor nearly to unity. The speed of the motor can also be varied from minimum value to the rated value by VF method. The results obtained prove that the power factor can be improved automatically and also accurate speed control can be obtained.
\end{abstract}

Keywords: Capacitive VAR, Induction Motor, Power Factor Correction, VFM.

\section{Introduction}

In earlier days, microprocessor has been used for power factor correction and to establish speed control. Microprocessor use zero crossing detector (ZCD) to find power factor value .But ZCD add some harmonics such as noise, so power factor which is measured from ZCD gives a false value from actual value of power factor. So proper capacitance value cannot be added and power factor cannot be corrected. In addition microprocessor cannot withstand adverse condition, so PLC is used for optimal operation in industry. The major cause in the industrial field is power consumption and power loss while using the speed control methods. In the VFD power consumption it is optimized.

To improve the power factor capacitor is connected in shunt with the load. The capacitor draws a leading current and cancels the lagging component in the load current. Using capacitor for power factor improvement has several benefits. Capacitor in DC circuits is used to keep control signal voltage/current constant and ripple free. As voltage across the capacitor cannot change suddenly and when there is change in voltage, capacitors opposes this change and try to keep voltage unchanged. The power factor of induction motor is in the range of 0.8 to 0.85 under load conditions and it may be 0.3 under no-load conditions due to leakage reactance. The capacitor can be connected to a common bus for controlling several motors. This minimizes the resonant conditions and also power flow will be smooth.

Variable frequency drive (VFD) accurately controls the speed of an AC induction motor or synchronous motor and performs forward and reverse operation at any frequency. The main function of VFD is to control the speed of the motor by varying frequency and voltage supply to the motor.. Other names for a VFD are variable speed drive, adjustable speed drive, adjustable frequency drive, AC drive, micro drive and inverter. A PLC is a digital computer which gets inputs and based on the inputs decisions are taken and the output is controlled for a process or system equipment. Programs are stored in non-volatile memory [22-32].

Before the PLC, control, sequencing, and safety interlock logic for manufacturing automobiles were mainly composed of relays, cam timers, drum sequencers, and dedicated closed loop controllers. As it contains number and number of devices the process becomes complex one, time consuming and expensive, as electricians needed to individually rewire the relays to change their characteristics.

\section{Hardware and Software Arrangement}

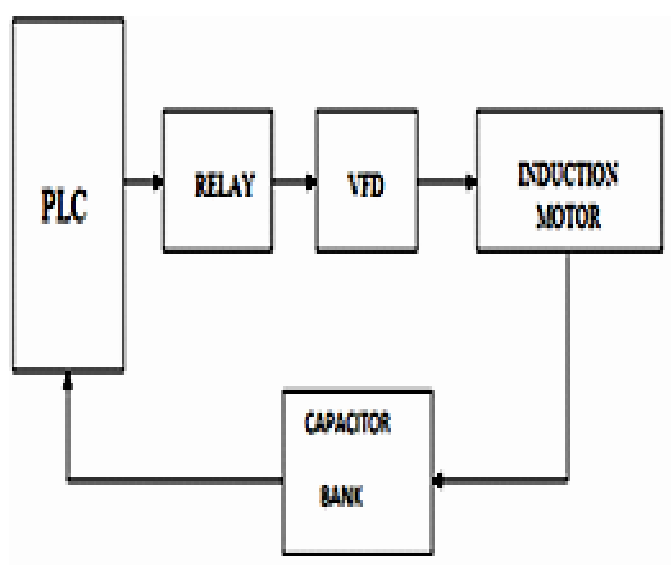

Fig. 1: Block diagram 
The structure PLC based induction motor is shown in Fig. 1.The system comprises of relay, Three phase induction motor, capacitor, Current transformer, PLC ,MFM and VFD.

\section{A. Relay}

A relay is an electrically operated switch. Relay has 5 pins. Common 2 pins are normally open and another 2 pins are normally closed. The supply is fed from the PLC once the $24 \mathrm{~V}$ DC supply comes across the relay. The PLC energizes the required relay and the corresponding capacitor is switched $\mathrm{ON}$ Automatically the power factor is corrected to a value nearly equal to unity.

\section{B. Three phase induction motor}

The three-phase 5 H.P, $440 \mathrm{v}, 10$ A motor is used to run the conveyor. The conveyor is connected with the shaft of the motor through gear system. The motor used in the conveyor is squirrel cage type.

\section{Capacitors}

In this work static capacitors are used to improve the power factor for induction motor. The capacitors are connected in series with the relay. Capacitors are turned $\mathrm{ON}$ while the relay coil is energized. In this work five capacitors are used across the five relays. The capacitors ranges in $\mathrm{kVAR}$ are $1,1.5$, and 0.5 .

\section{Current transformer}

The three current transformers of the rating (60/5/1.5)A are used. These current transformers are connected in the three phases of the supply. It measures the value of current given to the multifunction meter.

\section{E. Programmable Logic Controller}

The PLC operated on 24V DC supply. The switch mode power supply is used to turn ON the PLC. Rack type delta PLC is used in this project because of its simplicity and easy to programming. In delta type PLC it has eight input ports and eight output ports. The relay is connected in the output of PLC. The Ladder logic diagram is used for programming the PLC. The ladder logic diagram method is the easiest way of programming.

\section{F. Variable Frequency Drive}

A VFD can control an electric motor by varying the frequency and voltage supplied to the electric motor. The frequency (or hertz) of a motor is directly related to the speed of the motor (RPM). In other words, the higher the frequency, the higher the speed of the motor. If an application does not need a motor to run at constant speed the VFD can be employed to meet the requirements of the electric motor's load. The VFD can change the speed of the application motor.

\section{G. PLC-DVP28SV}

Delta DVP28SV, 28SV, the pin diagram of which is shown in Fig. 2 , is a 28 -point (16 inputs +12 outputs) PLC MPU, offering various instructions and is with $16 \mathrm{~K}$ Steps program memory DVP28SV is small in size and easy to install. AsDVP28SV is an open one, it should be enclosed in a packing to avoid dust, humidity, electric shock and vibration.

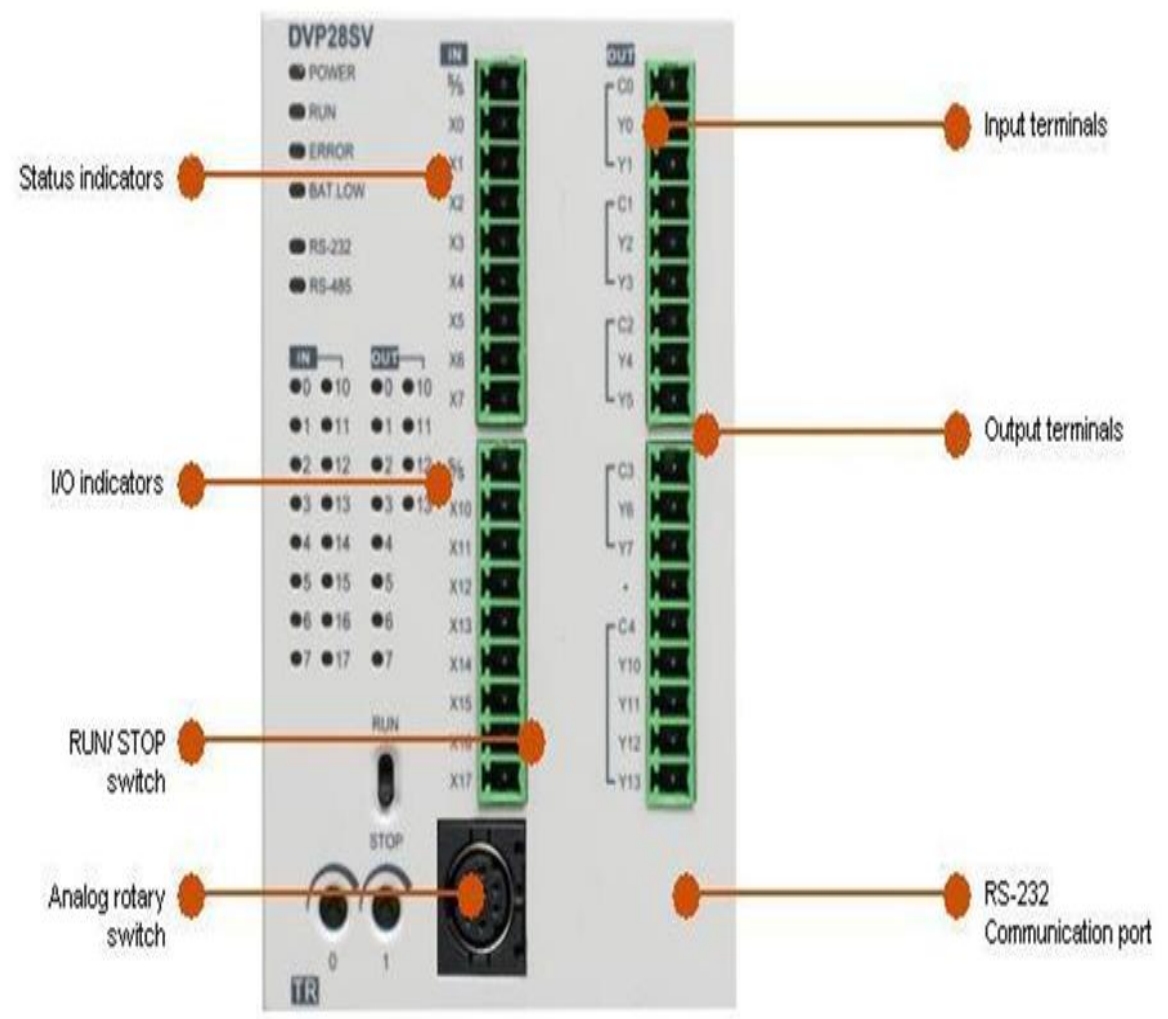

Fig. 2: Pin diagram of DVP28SV

\section{H. SELEC MFM 384-C}

The SELEC MFM384-C Electrical Panel Meters is a Multifunction Meters which indicates voltage, current, power, power factor, frequency and energy of induction motor.
In this the power factor is measured by using the MFM and the value of the power factor is send to the PLC.

There are three capacitors and four relays and contactor. These capacitors and relays are connected in series with the supply. If the relay is closed then the capacitor gets ON. MMF measures the value of the power factor. Then the MMF sends the measured 
power factor value to the PLC. The PLC will compare the measured power factor with the reference power factor which was already fed into the system. And according to the difference value the PLC will ON the relay.

\section{Explanation for ladder diagram}

The program is loaded through ladder diagram which is shown in fig. 3

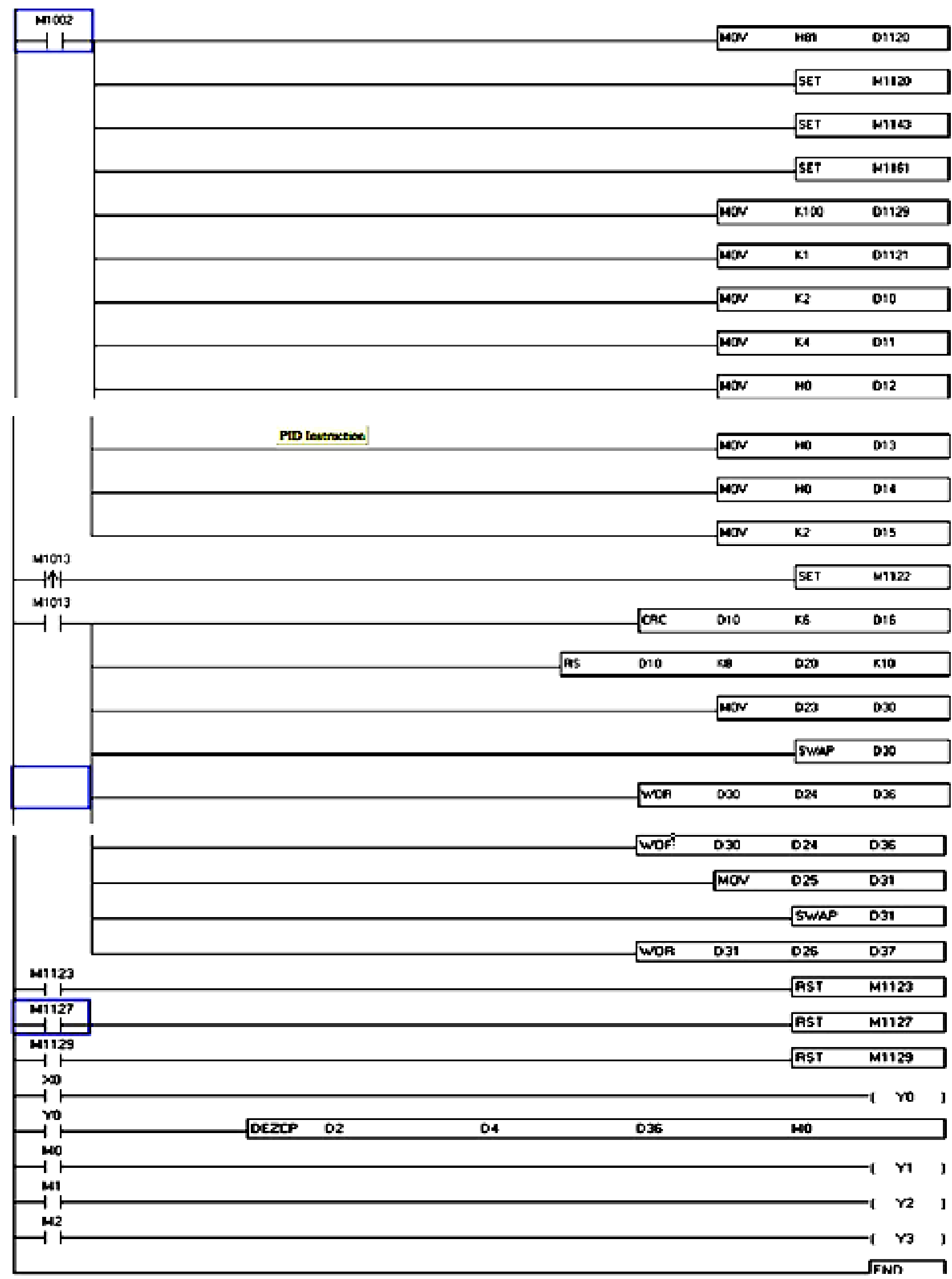

Fig. 3: Ladder Logic Diagram 
X0-Motor switch

Y0-Motor

D0-Fixed register

D2-Input value from MFM

M0-Memory coil (Dummy coil)

D36 - power factor value.

If the actual value is lower than capacitance value the corresponding capacitor is turned ON.

When motor switch ( $\mathrm{X} 0)$ is $\mathrm{ON}$, then the motor is turned $\mathrm{ON}$ Then the motor give input to decimal comparator (DECMP), the value of D0 is always fixed to $0.9, \mathrm{D} 36$ is the input value from MFM.

When D0<D36 the switch M2 is turned on and the corresponding capacitor $\mathrm{Y} 1$ is added.

When D0>D36, M0 is turned ON which switches the M1000 and D36 value is fed to DEZCP. Now D36 $=0.85$ which is out of range then M5 is turned $\mathrm{ON}$ and corresponding capacitor $\mathrm{Y} 3$ is turned $\mathrm{ON}$ is added.

D0>D36, M1000 is turned ON and D2 value is fed to DEZCP The value of D36 is within the range of D500 and D504, so M3 is turned $\mathrm{ON}$.

Now, D0=D36 and D2 value is out of range so M3 and M1 is turned $\mathrm{ON}$.

\subsection{Calculation of Capacitance}

Original power factor, $\cos \phi=0.687 \mathrm{lag}$; Motor input, $\mathrm{P}=0.5 \mathrm{~kW}$ Final power factor, $\cos \phi^{\prime}=0.971 \mathrm{lag}$; Efficiency, $\eta=100 \%$ $\phi=46^{\circ} 60^{\prime}$

$\tan \phi=\tan 46^{\circ} 60^{\prime}=1.057 \quad ; \quad \tan \phi^{\prime}=\tan 13^{\circ} 83^{\prime}=0.34$

Leading kVAR supplied by the condenser bank

$=\mathrm{P}\left(\tan \phi-\tan \phi^{\prime}\right)$

$=0.5(1.057-0.34)$

$=0.615 \mathrm{kVAR}$

Corresponding capacitor value for $0.615 \mathrm{kVAR}$ is $=4 \mu \mathrm{f}$

\section{Speed Control of Induction Motor Using VFD Variable Frequecy Drive}

The speed of induction motor can be controlled in various ways such as reducing the voltage applied to the motor, controlling the current to the motor. Using a wound-rotor motor and control the resistance applied to the rotor windings and Controlling the frequency and voltage applied to the motor. But the VFD control is an efficient way to control the speed of the motor.

\subsection{Operation of VFD}

The general block diagram of VFD is shown in Fig. 4.The first stage of a Variable Frequency AC Drive, or VFD, is the Converter. The converter is comprised of six diodes, which are similar to check valves used in plumbing systems. They allow current to flow in only one direction, the direction shown by the arrow in the diode symbol.

For example, whenever A-phase voltage (voltage is similar to pressure in plumbing systems) is more positive than $\mathrm{B}$ or $\mathrm{C}$ phase voltages, then that diode will open and allow current to flow. When B-phase becomes more positive than A-phase, then the Bphase diode will open and the A-phase diode will close. The same logic applies for negative diodes also. Hence this converter is a six pulse converter and hence six pulse VFD which is used current Variable Frequency Drives.

Let us assume that the drive is operating on a $440 \mathrm{~V}$ power system. The $440 \mathrm{~V}$ rating is "RMS" or root-mean-squared. The peaks on a $480 \mathrm{~V}$ system are $679 \mathrm{~V}$. In general, the VFD dc bus has a dc voltage with an AC ripple. The voltage swings from $580 \mathrm{~V}$ to $690 \mathrm{~V}$.

We can get rid of the AC ripple on the DC bus by adding a capacitor. The capacitor is same as accumulator of plumbing system. The general characteristics of capacitor are it blocks AC ripples and hence the output DC voltage is uniform. The AC ripples on the DC bus is typically less than 3 Volts. Thus, the voltage on the DC bus becomes "approximately" 650VDC. The factors affecting the actual voltage is based on voltage level of the AC line feeding the drive, the amplitude of voltage unbalance on the power system, the load of the motor, the impedance of the power system. Also it depends on reactors and harmonics filters installed in the system. The diode bridge converter that converts AC- DC is sometimes just referred to as a converter. In practice any device converting $\mathrm{DC}$ to $\mathrm{AC}$ is also a converter, but termed as inverter.

When the switches in the positive leg is closed the corresponding phase of the motor is connected to the positive dc bus and the voltage on that phase becomes positive. When the switches in the negative leg is closed the corresponding phase of the motor is connected to the negative dc bus and the voltage on that phase becomes negative. Thus any phase of the motor can be positive or negative and the desired frequency can be generated. Automatically we can control any phase to be positive, negative or zero.

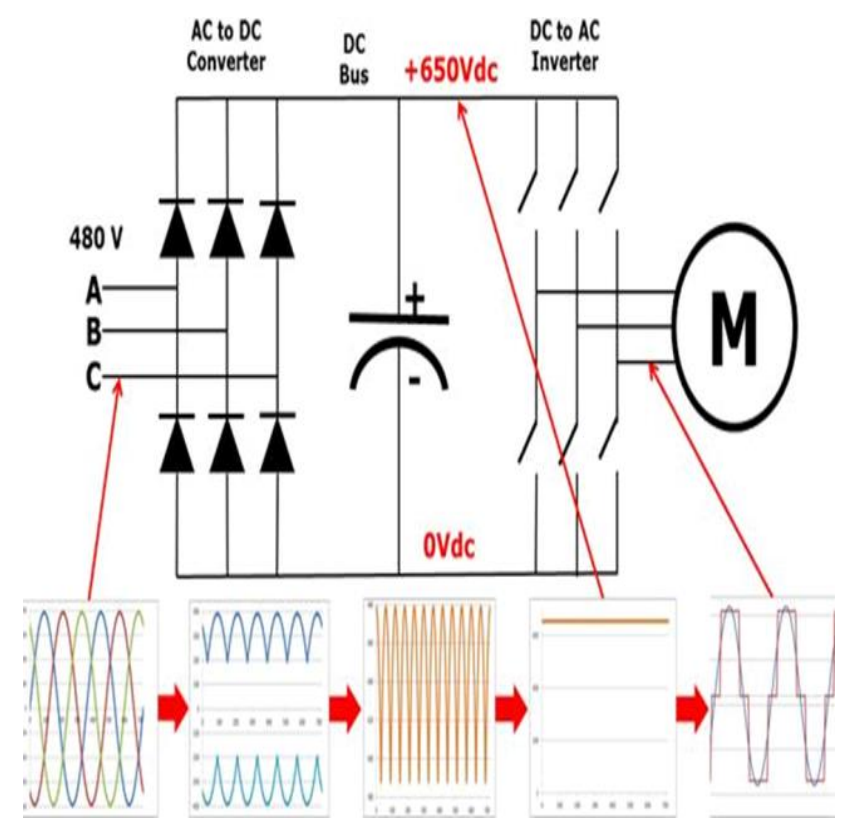

Fig. 4: VFD Circuit Diagram

Notice that the output from the VFD is a "rectangular" wave form. VFD's do not produce a sinusoidal output. Even though the rectangular wave is not suitable for a distribution system it works well with a motor.

For example if the frequency is to be reduced to $40 \mathrm{~Hz}$ then the voltage also has to be reduced to $240 \mathrm{~V}(\mathrm{v} / \mathrm{Hz}$ ratio).But the voltage at present we have is $650 \mathrm{~V}$ DC.

This is called Pulse Width Modulation or PWM. Imagine that we could control the pressure in a water line by turning the valve on and off at a high rate of speed. The PWM technique works very well for VFD. Notice that during the first half cycle, the voltage is ON half the time and OFF half the time.

Thus, the average voltage is half of $480 \mathrm{~V}$ or $240 \mathrm{~V}$. By pulsing the output, we can achieve any average voltage on the output of the VFD.

\subsection{Reasons to use VFD}

\section{Reduce Energy Consumption and Energy Costs}

By running the motor to the desired speed by employing VFD the energy costs are getting reduced

2. Increase Production through Tighter Process Control

When the motor is operated at the efficient speed the production will become higher and profitable. 
Table. 1: Tabulation of Checklist

\begin{tabular}{|l|c|}
\hline \multicolumn{1}{|c|}{ PARAMETERS } & ADDRESS \\
\hline Motor nominal voltage & 9905 \\
\hline Motor nominal current & 9906 \\
\hline Motor nominal frequency & 9907 \\
\hline Motor nominal speed & 9908 \\
\hline Motor nominal power & 9909 \\
\hline Motor minimum speed & 2001 \\
\hline Motor maximum speed & 2002 \\
\hline Motor acceleration time & 2202 \\
\hline Motor deceleration time & 2203 \\
\hline Phase inversion & 9914 \\
\hline Saving the settings & 9902 \\
\hline
\end{tabular}

\section{Extend Equipment Life and Reduce Maintenance}

By employing VFD the fault level is less and the downtime of the equipment is less As VFD controls the voltage and frequency in an efficient way the equipment is better protected from electro thermal overloads, phase protection, under voltage, overvoltage, etc. As VFD eliminates belt, gear and bearing wear the complexity and cost of the system is reduced.

The constant torque region is fairly self-explanatory; the VFD is regulating the flux so that the current is constant. Once the VFD surpasses the rated system frequency, the voltage cannot increase due to the physical constraints of the system. Because the voltage is static - and the frequency is increasing - the flux is forced to decrease. When this occurs, the current and torque are forced to decrease as well. This is called field weakening. Although not necessarily a good thing, it can be useful if there is a need to power a partial torque load above the rated speed. In addition to this capability, VFDs can also take any form of input power whether it's single-phase AC, 3-phase AC, or DC. VFDs fed from a DC source still power an AC load without an internal rectifier.

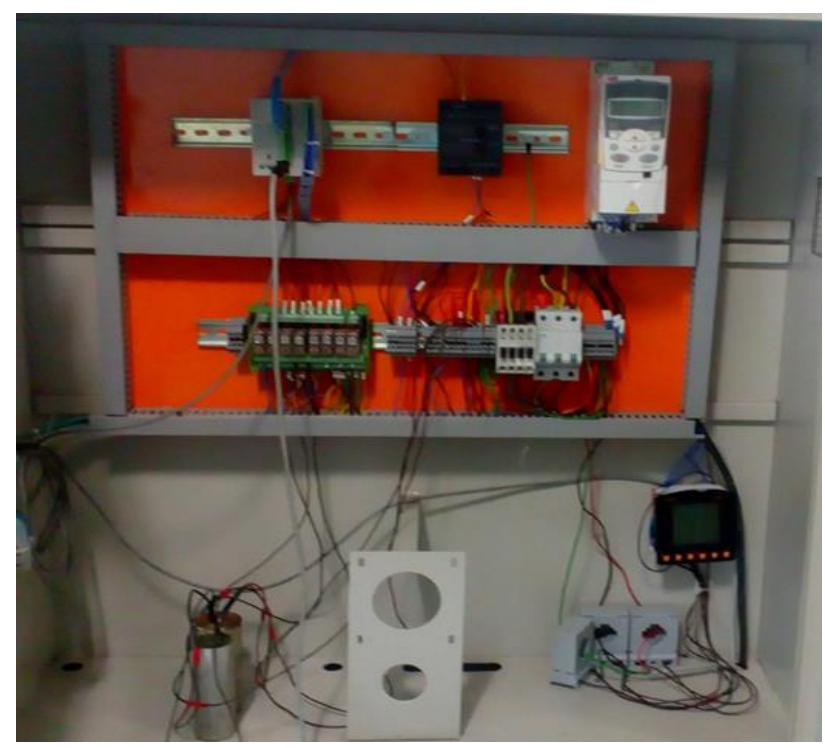

Fig. 5: PLC Arrangement

The present work is demonstrated by automating a conveyor system. The power factor is corrected and By employing a VFD the speed control also attained.Withot PLC the power factor is found to be 0.7 and after employing the system the power factor becomes 0.95 .As the power factor increases the utilization factor and efficiency of the system also improved. Similarly the speed control is programmed as shown in table I.

The general PLC panel arrangement is shown in Fig. 5.To prove the speed control it is applied to a conveyor motor as shown in Fig.6. The speed control is programmed for controlling the speed which is shown in table I.

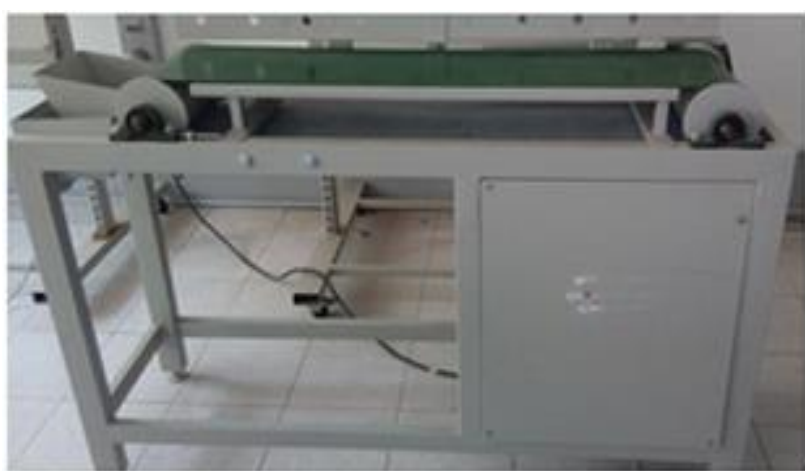

Fig. 6: Conveyor Arrangement

\section{Conclusion}

The simulation on PLC for power factor correction in induction motor is implemented using the software WPL SOFT.

In the conveyor based system the real power factor of the motor is 0.693 to 0.72 . By using the power factor correction, the power factor of the machine is increased by 0.96 to 0.98 .

The VFD is used to vary the speed of conveyor from zero to rated speed. It consumes less power than the normal converters. So it is effective in reduction of power loss. This project can be implemented easily in variable speed drive such as multi- storey lift, elevator and escalator

\section{References}

[1] Zhang P., Du Y., Habetler TG, Lu B., "A Survey of Condition Monitoring and Protection Methods for Medium-Voltage Induction Motors", IEEE Transactions On Industry Applications,.47 (1): 34-45 (2011)

[2] Chaitanya N.Jibhakateand Mrs.VijayaHuchche "Speed Control of Single Phase Induction Motor Using Micro-Controller" IJERA pp.29-32 April 2014

[3] Shwetahugar, BasavarajAmarapur "Protection of Induction Motor using Microcontroller'IJETAE, Volume 6, no. 5, pp. 64 68 , May 2016

[4] Mahendra P. Bodkhe and K. N. Pawar "Parameter Monitoring Using Zigbee Protocol for Three Phase Induction Motor " IJETAE, Vol.4, no.1,pp.73-77,January 2014

[5] M. G. Ioannides, "Design and implementation of PLC-based monitoring control system for induction motor", IEEE Trans. Energy Convers., vol. 19, no. 3, Sep. 2004 469-476.

[6] A. R. Al-Ali, M. M. Negm, and M. Kassas, "A PLC based power factor controller for a 3-phase induction motor", in Proc. Conf. Rec. IEEE Industry Applications, vol. 2, 2000, 1065-1072.

[7] Paul Priba and Terry Pameticky, "A PLC Application for large motor monitoring”, IEEE, Paper No. PCIC, 88-16.

[8] Jasmin Velagic, Admir Kaknjo, Nedim Osmic and Tarik Dzananovic, "Netwok based Control and Supervision of induction motor using OPC Server and PLC", 53rd International Symposium ELMAR-2011,14-16 Sept. 2011,Zadar,Croatia

[9] Ramazan Bayindir, Ibrahim Sefa, Ilhami Colak and Askin Bektas, "Fault detection and protection of induction motor using sensors", IEEE Trans. on Energy Conversion, vol.23, No.3, Sept. 2008

[10] M. Pineda-Sánchez, R. Puche-Panadero, M. Riera-Guasp, A. Sapena-Baño, J. Roger Folch, J.Pérez-Cruz, "Motor Condition Monitoring of Induction Motor with Programmable Logic Controller and Industrial Network", European Community's Seventh Framework Program FP7/2007-2013 under Grant Agreement 224233

[11] Yasar Birbir, H.Selcuk Nogay, "Design and Implementation of PLC-Based Monitoring Control System for Three-Phase Induction Motors Fed by PWM Inverter", International Journal of Systems Applications, Engineering \& Development Issue 3, Volume 2, 2008

[12] Muhammad Arrofiq,NordinSaad, "PLC-based Fuzzy Logic Controller for Induction motor Drive with Constant V/Hz Ratio", International Conference on Intelligent and Advanced Systems, 2007 
[13] I. Colak, H. Celik, 'I. Sefa, and S. Demirbas, "On line protection system for induction motors", Energy Convers. Manage., vol. 46, no. $17, .2773-2786,2005$.

[14] W.C. Bloomquist and W. K. Boist, "Application of capacitors for pf improvement of induction motor”, A.I.E.E. Trans. PAS, $1945,274-278$

[15] M.A. El-Shirkawi, S. S. Venkata, T .J. Williams, and N.G Butler, "An adaptive p.f. Controller for three phase induction Generators", IEEE Trans.PAS,vol.104, 1985,1825-1831.

[16] D. Burrow and A. Wu, "On-Line utility tie power factor control Pulp and Paper Industry" IEEE Technical Conference, 394, 1996.

[17] R.Mandal,S.K.Basu,A.Kar and S. P. Chowdhury, A microcomputer-based power factor controller, IEEE Trans. On Industrial Electronics, vol.41, 1994, 361-371.

[18] H.Frank and B. Landstorm, "Power factor correction with thyristor controlled capacitors", AESA Journal, 1971, 180-184.

[19] Allen Bradley-Rockwell, Automation Micro-810, User manual.Avialable:http://www.rockwellautomation.com/literature 1

[20] W. Bolton, Programmable Logic Controllers, Fourth Edition, ISBN-10: 0-7506-8112-8, Elsevier Newnes, 2006.

[21] L. A. Bryan, E. A. Bryan, Programmable controllers: theory and Implementation, 2nd ed., ISBN 0-944107-32-X, Industrial Text Company, 1997.

[22] Gary Dunning, Introduction to Programmable Logic Controller, Delmar Cengage Learning publisher.

[23] R. Kalaivani, K. Ramash Kumar, S. Jeevananthan, "Implementation of VSBSMC plus PDIC for Fundamental Positive Output Super Lift-Luo Converter,' Journal of Electrical Engineering, Vol. 16, Edition: 4, 2016, pp. 243-258.

[24] K. Ramash Kumar,'Implementation of Sliding Mode Controlle plus Proportional Integral Controller for Negative Output Elementary Boost Converter," Alexandria Engineering Journal (Elsevier), 2016, Vol. 55, No. 2, pp. 1429-1445.

[25] P. Sivakumar, V. Rajasekaran, K. Ramash Kumar, "Investigation of Intelligent Controllers for Varibale Speeed PFC Buck-Boos Rectifier Fed BLDC Motor Drive," Journal of Electrical Engineering (Romania), Vol.17, No.4, 2017, pp. 459-471.

[26] K. Ramash Kumar, D.Kalyankumar, DR.V.Kirbakaran” An Hybrid Multi level Inverter Based DSTATCOM Control, Majlesi Journal of Electrical Engineering, Vol. 5. No. 2, pp. 17-22, June 2011, ISSN: 0000-0388.

[27] K. Ramash Kumar, S. Jeevananthan, "A Sliding Mode Control for Positive Output Elementary Luo Converter," Journal of Electrical Engineering, Volume 10/4, December 2010, pp. 115127.

[28] K. Ramash Kumar, Dr.S. Jeevananthan,” Design of a Hybrid Posicast Control for a DC-DC Boost Converter Operated in Continuous Conduction Mode" (IEEE-conference PROCEEDINGS OF ICETECT 2011), pp-240-248, 978-1-42447925-2/11.

[29] K. Ramash Kumar, Dr. S. Jeevananthan,” Design of Sliding Mode Control for Negative Output Elementary Super Lift Luo Converter Operated in Continuous Conduction Mode", (IEEE conference Proceeding of ICCCCT-2010), pp. 138-148, 978-14244-7768-5/10.

[30] K. Ramash Kumar, S. Jeevananthan, S. Ramamurthy” Improved Performance of the Positive Output Elementary Split InductorType Boost Converter using Sliding Mode Controller plus Fuzzy Logic Controller, WSEAS TRANSACTIONS on SYSTEMS and CONTROL, Volume 9, 2014, pp. 215-228.

[31] N. Arunkumar, T.S. Sivakumaran, K. Ramash Kumar, S Saranya, "Reduced Order Linear Quadratic Regulator plus Proportional Double Integral Based Controller for a Positive Output Elementary Super Lift Luo-Converter," JOURNAL OF THEORETICAL AND APPLIED INFORMATION TECHNOLOGY, July 2014. Vol. 65 No.3, pp. 890-901.

[32] Arunkumar, T.S. Sivakumaran, K. Ramash Kumar, "Improved Performance of Linear Quadratic Regulator plus Fuzzy Logic Controller for Positive Output Super Lift Luo-Converter,' Journal of Electrical Engineering, Vol. 16, Edition:3, 2016, pp 397-408. 